\title{
The Current Account And The Intertemporal Budget Constraint: Evidence From G-7 Countries
}

\author{
Atul A. Dar, (Email: atul.dar@smu.ca), Saint Mary’s University, Canada \\ Sal AmirKhalkhali, (Email: sal.amirkhalkhali@smu.ca), Saint Mary's University, Canada \\ Samad AmirKhalkhali, (Email: samad.amirhalkhali@smu.ca), Saint Mary’s University, Canada
}

\begin{abstract}
A random coefficients, error-correction model of saving-investment behaviour, which is consistent with intertemporal open-economy models, is estimated for $G-7$ countries to infer about the current account, capital mobility and the relevance of intertemporal budget constraints in such model. The error-correction mechanism is especially suited here since it is able to integrate short run dynamics with long run behaviour, while the random coefficients approach is a natural specification for accommodating inter-country differences. If saving-investment correlations measure capital mobility, a positive correlation would mean that a country's growth prospects would be constrained by its saving, government deficits would crowd out private investment and, at a broader level, good investment opportunities might have to be foregone unless the required resources were obtained through a sacrifice in current consumption. On the other hand, those correlations could also be seen as validating the use of intertemporal budget constraints in open-economy models.
\end{abstract}

\section{INTRODUCTION}

n recent years, empirical models of the current account have increasingly come to have macroeconomic foundations that emphasize intertemporal budget constraints. This has been motivated partly to test whether the notion of intertemporal constraints is consistent with facts, as well as to sharpen the interpretation of results. In this regard, the finding of a strong positive correlation between saving and investment in the long run appears to support the relevance of intertemporal budget constraints. Such a relationship implies, via the national accounts identity, that the current account (relative to GDP) is stable in the long run. The finding of a strong positive correlation between saving and investment is, if course, consistent with other possibilities as well. Of these, the one that has attracted a lot of attention is the interpretation proposed by Feldstein and Horioka (1980) in their now famous paper, that the strength of the relationship between these macroeconomic variables is an indicator of the degree of capital mobility across nations. Specifically, they proposed that a strong positive relationship would signify low capital mobility, while one that was zero would imply perfect capital mobility. Their study on 17 OECD countries found an almost one-to-one correspondence between investment rates and saving rates. Since that study, a significant debate has raged about what exactly a strong relationship between saving and investment might mean. Through it all, one fact has remained constant. The positive correlation between saving and investment has proven to be durable and robust to data sets and econometric methodology, prompting some researchers to view this empirical regularity as a stylized fact that open economy macroeconomics must be able to explain.

The issue of whether saving and investment are correlated is an important one for a number of reasons. If this correlation is a reflection of low capital mobility, then a country's growth prospects would be constrained by it's saving. In addition, government deficits would crowd out private investment and, at a broader level, good investment opportunities might have to be foregone unless the required resources were obtained through a sacrifice in current consumption. Finally, a persistent, positive correlation might alternatively support to the use of intertemporal budget constraints in open economy macro models. 
As noted above, the existence of a strong, positive relationship between saving and investment is entirely consistent with intertemporal budget constraints and high capital mobility (Jansen, 1996, 1998), as it is with low capital mobility (Feldstein and Horioko, 1980). Indeed, it could also reflect current account targeting by policymakers (Summers, 1988). Recent empirical work has attempted to sort through the possibilities by appealing to the underlying theory of open economy models. The advantage of this approach is that, since the empirical framework is grounded in theory, it provides a benchmark with which to interpret and assess the results of any relationship between saving investment in both the short and long run, and it also reduces the likelihood of specification bias. Both these problems have in the past plagued empirical studies, not least because the saving investment relationship has typically been specified in an ad hoc manner, with no firm theoretical basis, other than the accounting identity that connects these two variables. The error correction model, which integrates short run dynamics with long run behaviour, provides a firmer basis for interpreting saving investment correlations, which could differ significantly between the short and long run.

The purpose of this paper is to extend Jansen $(1996,1998)$ as well as Amirkhalkhali and Dar (1993) by examining the saving-investment relationship and its implications for the current account in the short run and long run using an error correction model with random coefficients. The evidence in Jansen clearly points to the need for accommodating significant inter-country differences. Jansen (1998) attempts to deal with this issue by using a fixed effects approach. However, a model with random coefficients is a more general way of incorporating unmeasured differences between countries, differences that a neither a random effects nor fixed effects approach could not adequately capture. Our focus is the G-7 countries - Britain, Canada, France, Germany, Italy, Japan and the USA over the 1983-2002 interval. We first investigate the aggregate G-7 and country-specific saving-investment relationship using random coefficients for the whole period. Following that, we examine the same issue for two subperiods - 1983-1992 and 1993-2002 - for all G-7 countries, which would shed light on intertemporal shifts in savinginvestment relationship and what it tells us about capital mobility. Finally, we estimate the error-correction model by dividing the G-7 countries into EU and non-EU groups, which would allow us to study whether the dynamics of the saving-investment relationship differs between these two groups of countries.

\section{THE MODEL} follows:

Our starting point is the error-correction model (ECM) proposed by Jansen (1996). This can be written as

$$
\Delta \mathrm{I} \mathrm{Y}_{\mathrm{it}}=\alpha+\beta \Delta \mathrm{S}_{\mathrm{it}}+\gamma\left(\mathrm{S}_{\mathrm{it}-1}-\mathrm{IY}_{\mathrm{it}-1}\right)+\delta \mathrm{S}_{\mathrm{it}-1}+\mathrm{W}_{\mathrm{it}}{ }^{\prime} \theta
$$

where IY and S are ratios of investment (gross fixed capital formation) and saving (basic saving calculated as GDP minus private and public consumption expenditure) to GDP, respectively. $\Delta$ stands for the first difference, and the subscripts $\mathrm{i}(\mathrm{i}=1,2, \ldots, \mathrm{N})$ and $\mathrm{t}(\mathrm{t}=1,2, \ldots, \mathrm{T})$ index the countries and time periods in the sample respectively. Note that $\left(\mathrm{S}_{\mathrm{it}-1}-\mathrm{IY}_{\mathrm{it}-1}\right)$ is the error correction term, representing the dynamic adjustment of the current account.

The parameters $\alpha, \gamma$ and $\delta$ have important long run implications for the saving-investment relationship. In particular, the coefficient of the error correction term $(\gamma)$ is the cointegrating parameter, and rejecting the hypothesis that $\gamma=0$, would imply a long-run relationship between saving and investment. The nature of that relationship then depends upon the parameter $\delta$. If the hypothesis $\delta=0$ is rejected, the current account is non-stationary, and this is only possible if capital mobility is present [see Jansen (1996)]. In this case, the long run correlation between investment and saving is given by $[1+(\delta / \gamma)]$, which is generally less than unity. On the other hand, if $\delta=0$, the current account fluctuates around a constant $-(\alpha / \gamma)$, which would equal zero if, in addition, $\alpha=0$. In this case, the long-run relationship between investment and saving is one-to-one, and this result is consistent with the existence of an intertemporal budget constraint with perfect capital mobility. However, it could also be indicative of low capital mobility as argued by Feldstein and Horioka (1980), and/or long-run current account targeting by the government (Summers, 1988). The parameter $\beta$ measures the short-run correlation between saving and investment, and it could reflect capital mobility and/or shocks to the economy. There is, however, an asymmetry in the implications of the size of this parameter. General equilibrium macro models can produce low correlations only if there is sufficient capital mobility. On the other hand, high positive correlations can occur even when capital mobility exists. In other words, if capital is highly immobile, this cannot produce low short run savinginvestment correlations, but high correlations cannot unambiguously be attributed to low capital mobility. It needs to be 
cautioned that since the short run correlations are contaminated by the effects of short run shocks hitting an economy, the size of the short run correlations do not allow us to draw decisive conclusions about degrees of capital mobility. Thus, a low short run correlation of say 0.25 need imply less capital mobility than a correlation of 0.15 . In that sense, the Feldstein and Horioka interpretation of a zero correlation implying perfect capital mobility is not correct; all that one can conclude is that high capital mobility exists (see Jansen, 1996, p. 757).

The vector $\mathrm{W}$ represents a set of excluded variables that in conjunction with the included explanatory variables, are sufficient to determine the dependent variable IY. However, in this model, the regression parameters, as well as the vector of excluded variables $\mathrm{W}$, are not unique since they are sensitive to the parameterization adopted. To make the coefficients unique, we assume that $\mathrm{W}$ and the explanatory variables are related as follows:

$$
\mathrm{W}_{\text {it }}=\eta_{1 \mathrm{it}}+\eta_{2 \mathrm{it}} \Delta \mathrm{S}_{\mathrm{it}}+\eta_{3 \mathrm{it}}\left(\mathrm{S}_{\mathrm{it}-1}-\mathrm{IY} \mathrm{Y}_{\mathrm{it}-1}\right)+\eta_{4 \mathrm{it}} \mathrm{S}_{\mathrm{it}-1}+\mathrm{v}_{\mathrm{it}}
$$

Substituting (2) into equation (1) gives

$$
\mathrm{IY}_{\mathrm{it}}=\alpha_{\mathrm{it}}+\beta_{\mathrm{it}} \Delta \mathrm{S}_{\mathrm{it}}+\gamma_{\mathrm{it}}\left(\mathrm{S}_{\mathrm{it}-1}-\mathrm{IY}_{\mathrm{it}-1}\right)+\delta_{\mathrm{it}} \mathrm{S}_{\mathrm{it}-1}+\mathrm{u}_{\mathrm{it}}
$$

where $\alpha_{\mathrm{it}}=\alpha+\eta_{1 \mathrm{it}}{ }^{\prime} \theta, \beta_{\mathrm{it}}=\beta+\eta_{2 \mathrm{it}}{ }^{\prime} \theta, \gamma_{\mathrm{it}}=\gamma+\eta_{3 \mathrm{it}}{ }^{\prime} \theta, \delta_{\mathrm{it}}=\delta+\eta_{4 \mathrm{it}}{ }^{\prime} \theta$, and $\mathrm{u}_{\mathrm{it}}=\mathrm{v}_{\mathrm{it}}{ }^{\prime} \theta$.

This is a varying coefficients specification that may be seen as a refinement of the stochastic law relating investment rates to its main determinants (Pratt and Schlaifer, 1988). For a discussion of the details of the random coefficients techniques employed in this study see Swamy (1970), Swamy and Mehta (1975), and Swamy and Tavlas (2002).

\section{Estimation and Results}

The aggregate and country-specific estimates of the ECM given by equation (3) using random coefficients techniques are presented In Tables 1 and 2 respectively. Table 1 clearly supports the use of random coefficients since under the null hypothesis that the correct model is one with fixed coefficients, the g-statistic is statistically significant. In addition, the estimate of the error correction parameter $\square \square$ is also statistically significant. This means that saving and investment are co-integrated - that is, a long run relationship exists between these variables. Furthermore, we cannot reject the hypothesis that $\square=0$ nor the hypothesis that $\square=0$, so that the long run saving-investment relationship implies a stationary current account that fluctuates around zero. There is, thus, a one-to-one relationship between saving and investment rates. As such, this is consistent with intertemporal budget constraints and thus supports the use of such constraints in modelling open economies. On the other hand, it is also consistent with long run current account targeting by the government and/or low capital mobility. It is difficult to isolate one factor as the driving force behind the stationary current account, although current account targeting is least likely for the period under consideration in which G-7 countries have been under flexible exchange rate regimes (Jansen, 1998).

Table 1: Random Coefficients GLS Results (1983-2002)

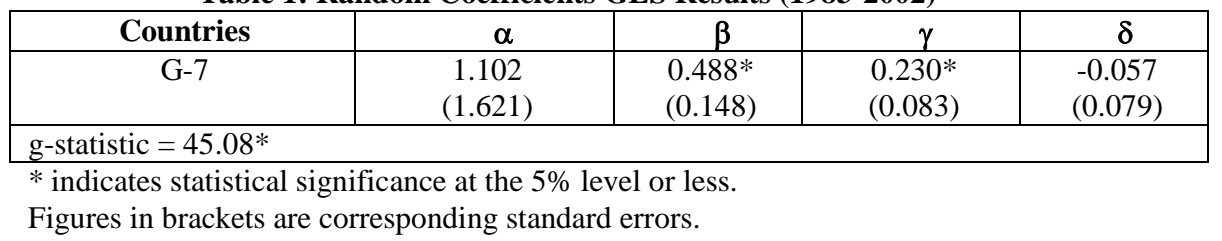

The estimate of $\beta$ of 0.488 , the short-run saving-investment correlation, is well below unity, pointing to capital mobility; yet, it is significantly greater than zero making an inference about the degree of capital mobility difficult for the reasons alluded to above. At best, these aggregate results seem to be consistent with the existence of an intertemporal budget constraint. 
Do the aggregate results mask inter-country differences? As can bee seen from Table 2, the estimates of the country-specific random coefficients have the same general qualitative implications as the aggregate estimates. The results confirm the existence of a long run relationship between investment and saving for each country and, with the exception of Germany, suggest that current account fluctuates around zero in the long run. Thus, the country-specific results also support the existence of an intertemporal budget constraint. Germany's case implies that the current account is non-stationary and this supports high capital mobility, with the long run correlation between investment and saving being only 0.44 . On the other hand, the differences between countries are quite large. The coefficient on the error correction term measures the lagged adjustment of the current account in a given period to past current account imbalances. The estimates indicate that the adjustment is the slowest in the United States with just 14 percent of current account imbalances adjusting in any given period, compared to about 31 in Germany, and 29 percent in France. Slow adjustment implies that imbalances persist over longer periods of time, and can plausibly be attributed to capital mobility.

There is significant variation in the country-specific short run correlations, with the estimate of $\beta$ being relatively high for the United States, Japan and Germany - the large countries in the sample, and lower for the other countries. High short run correlations are supportive of the limited capital mobility argument, but it is plausible that the high correlations reflect the "large country" effect and not low capital mobility [see, for example, Murphy (1984)], or country-specific shocks. On the other hand, low short run correlations, such as those for Italy and France, would be suggestive of capital mobility.

Table 2: Country-Wise Regression Results (1983-2002)

\begin{tabular}{|c|c|c|c|c|}
\hline Countries & $\square \square \boldsymbol{\alpha}$ & $\square \square \square \boldsymbol{\beta}$ & $\square \square \square \boldsymbol{\gamma}$ & $\square \square \square \boldsymbol{\delta}$ \\
\hline France & -0.996 & $0.167^{*}$ & $0.290^{*}$ & 0.035 \\
Italy & 0.261 & 0.041 & $0.173^{*}$ & -0.025 \\
Germany & $3.612^{*}$ & $0.574^{*}$ & $0.313^{*}$ & $-0.174^{*}$ \\
UK & 1.906 & $0.551^{*}$ & $0.233^{*}$ & -0.097 \\
Canada & 1.453 & $0.428^{*}$ & $0.227^{*}$ & -0.085 \\
USA & 0.081 & $0.787^{*}$ & $0.137^{*}$ & 0.012 \\
Japan & 1.396 & $0.667^{*}$ & $0.234^{*}$ & -0.059 \\
\hline
\end{tabular}

* indicates statistical significance at the $5 \%$ level or less.

One way of assessing whether low capital mobility is behind the observed co-integration of saving and investment in G-7 countries is to estimate the ECM by splitting the sample periods into two sub-periods. If such saving-investment correlations do measure capital mobility then their magnitude can be expected to decline over time, given the acceleration in the integration of financial markets through the 1990s. A stable saving investment correlation, on the other hand, would indicate that capital mobility is high and the correlations merely reflect the intertemporal budget constraint. To assess this, we divided the sample period into two sub-periods - 1983-1992 and 1993-2002. The results are reported in Table 3. The estimate of the short run correlation is dramatically lower in the more recent period, which suggests that this coefficient likely measures capital mobility, while the size of the error correction coefficient actually increases and this is not what we would expect if this captured long run capital mobility. However, note that the estimate of $\square$ is statistically significant in the 1993-2002 sub-period, implying that the current account is non-stationary, which can happen only if there is capital mobility. Thus, the overall results for the two sub-periods suggest that saving-investment correlations do tell us something about capital mobility.

Table 3: Period-Wise Regression Results (G-7 Countries)

\begin{tabular}{|c|c|c|c|c|}
\hline Periods & $\alpha$ & $\boldsymbol{\beta}$ & $\gamma$ & $\delta$ \\
\hline Period I & 0.906 & $0.383^{*}$ & $0.203^{*}$ & -0.042 \\
$1983-1992$ & $(0.472)$ & $(0.066)$ & $(0.047)$ & $(0.022)$ \\
\hline Period II & $1.908^{*}$ & 0.062 & $0.268^{*}$ & $-0.106^{*}$ \\
1 1993-2002 & $(0.525)$ & $(0.074)$ & $(0.048)$ & $(0.026)$ \\
\hline g-statistic: 14.70* & * indicates statistical significance at the 5\% level or less. \\
Figures in brackets are corresponding standard errors.
\end{tabular}


We also estimated ECM for the EU -G7 group (UK, France, Germany and Italy) separately from the non-EU group (US, Canada and Japan) to ascertain whether the dynamics of the current account differ. The results are reported in Table 4. Again, there is evidence of a long run relationship between saving and investment in both groups. However, the low and statistically insignificant estimate of the short run correlation and the statistical significance of $\square \square$ in the EU group coupled with exactly the opposite pattern in the non-EU group point to very different current account dynamics. Specifically, the EU results point to high capital mobility and a non-stationary current account, whereas in Japan and North America, it seems that the evidence is in support of the intertemporal budget constraint and perhaps relatively limited capital mobility.

Table 4: Group-Wise Regression Results (1983-2002)

\begin{tabular}{|c|c|c|c|c|}
\hline Groups & $\alpha$ & $\beta$ & $\gamma$ & $\delta$ \\
\hline$\frac{\text { EU-G7 }}{\text { France, Italy, Germany, and UK }}$ & $\begin{array}{l}3.335^{*} \\
(0.715)\end{array}$ & $\begin{array}{c}0.122 \\
(0.074)\end{array}$ & $\begin{array}{l}0.290^{*} \\
(0.049)\end{array}$ & $\begin{array}{l}-0.169^{*} \\
(0.035)\end{array}$ \\
\hline$\frac{\text { Non-EU-G7 }}{\text { Canada, USA, and Japan }}$ & $\begin{array}{c}0.509 \\
(0.425) \\
\end{array}$ & $\begin{array}{l}0.605^{*} \\
(0.088)\end{array}$ & $\begin{array}{l}0.136^{*} \\
(0.048)\end{array}$ & $\begin{array}{l}-0.027 \\
(0.020) \\
\end{array}$ \\
\hline \multicolumn{5}{|l|}{ g-statistic: $18.71 *$} \\
\hline
\end{tabular}

\section{CONCLUSIONS}

This paper estimates an error-correction model with random coefficients to examine whether savinginvestment behaviour in G-7 countries over the 1983-2002 period is consistent with intertemporal open-economy macroeconomics, and what implications can be drawn about the mobility of capital from that behaviour. The random coefficients approach is a natural choice in light of the evidence presented in Jansen $(1996,1998)$. The evidence presented in this paper is unambiguous in its strong support for the existence of a long run relationship between saving and investment for the G-7 countries in the aggregate, individually, as well as for the EU and non-EU countries belonging to G-7, as well for the sub-periods 1983-1992 and 1993-2002. Furthermore, for all individual countries (except Germany) and the G-7 countries as a whole, the current account fluctuates around zero in the long run. This also holds for the non-EU group of G-7 countries (but not for the EU group), as well as for the G-7 countries as a whole during the 1983-1992 sub-period (but not over the 1993-2003 sub-period). A zero long run current account coupled with the existence of a long run relationship between saving and investment suggests that that relationship is one-to-one, thereby implying that investment opportunities must be self-financed in the long run. However, two issues warrant attention. First, the short run saving-investment relationship and the dynamics of the current account are very different across countries as well as the two sub-periods, as implied above. For instance, the adjustment to long run values is slow in France and Japan, but much faster in the US and Italy. Second, the short saving-investment correlation varies substantially across individual countries, across sub-periods as well as between the EU group and the non EU group, suggesting that country-specific, group-specific or period-specific shocks likely play an important role.

Our finding of a one-to-one relationship between saving and investment in the long run does not itself mean that capital mobility is low, since these outcomes are perfectly compatible with an intertemporal budget constraint as well as current account targeting by policy makers. On the other hand, the fact that the current account is nonstationary for Germany, the EU group and the 1993-2002 sub-period, could mean that capital mobility amongst the EU group and in the 1993-2003 sub-period is high. The latter finding is also supported by the finding of a substantially lower short run correlation between saving and investment in that sub-period compared to the 1983-1992 sub-period. Overall, the use of an error correction mechanism to the saving investment relationship does provide support to current macroeconomic models with intertemporal budget constraints, and also provides a framework for interpreting short run as well as long run correlations between these two variables. Further work on extending the study to include all OECD countries is currently under way. 


\section{REFERENCES}

1. AmirKhalkhali, S. and A. Dar (1993), Testing for Capital Mobility: A Random Coefficients Approach, Empirical Economics, 18, 523-541.

2. Feldstein, Martin and Charles Horioka (1980), Domestic Saving and International Capital Flows, Economic Journal, February, 314-329.

3. Jansen, W. (1996), Estimating Saving-Investment Correlations: Evidence for OECD Countries Based on an Error Correction Model, Journal of International Money and Finance, 15, 749-781.

4. Jansen, W. (1998), Interpreting Saving-Investment Correlations, Open Economies Review, 9, 205-218.

5. Murphy, Robert G. (1984), Capital Mobility and the Relationship between Saving and Investment, Journal of International Money and Finance, 3, 327-342.

6. Pratt, J. W. and R. Schlaifer (1988), On the Interpretation and Observation of Laws, Journal of Econometrics, September, 23-52.

7. Summers, Lawrence H. (1988), Tax Policy and International Competitiveness, in Jacob A. Frenkel (ed.) International Aspects of Fiscal Policy, NBER Conference Report, Chicago: University of Chicago Press, 349375.

8. Swamy, P.A.V.B. (1970), Efficient Inference in a Random Coefficients Regression Model, Econometrica, March, 311-323.

9. Swamy, P.A.V.B. and J.S. Mehta (1975) Bayesian and Non-Bayesian Analysis of Switching Regressions and of Random Coefficient Regression Models, Journal of the American Statistical Association, September, 593-602.

10. Swamy, P.A.V.B., G.S. Tavlas (2002), Random Coefficient Models, in B.H. Baltagi (ed.) Companion to Theoretical Econometrics, Basil Blackwell, 410-428.

\section{NOTES}

